\title{
Impacts of Ti on electrical properties of Ge metal-oxide-semiconductor capacitors with ultrathin high- $k$ LaTiON gate dielectric
}

\author{
H.X. Xu • J.P. Xu • C.X. Li • C.L. Chan • P.T. Lai
}

Received: 28 September 2009 / Accepted: 10 March 2010 / Published online: 8 April 2010

(c) The Author(s) 2010. This article is published with open access at Springerlink.com

\begin{abstract}
Ge Metal-Oxide-Semiconductor (MOS) capacitors with $\mathrm{LaON}$ gate dielectric incorporating different $\mathrm{Ti}$ contents are fabricated and their electrical properties are measured and compared. It is found that Ti incorporation can increase the dielectric permittivity, and the higher the Ti content, the larger is the permittivity. However, the interfacial and gate-leakage properties become poorer as the Ti content increases. Therefore, optimization of Ti content is important in order to obtain a good trade-off among the electrical properties of the device. For the studied range of the $\mathrm{Ti} / \mathrm{La}_{2} \mathrm{O}_{3}$ ratio, a suitable $\mathrm{Ti} / \mathrm{La}_{2} \mathrm{O}_{3}$ ratio of $14.7 \%$ results in a high relative permittivity of 24.6 , low interfacestate density of $3.1 \times 10^{11} \mathrm{eV}^{-1} \mathrm{~cm}^{-2}$, and relatively low gate-leakage current density of $2.0 \times 10^{-3} \mathrm{~A} \mathrm{~cm}^{-2}$ at a gate voltage of $1 \mathrm{~V}$.
\end{abstract}

\section{H.X. Xu · J.P. Xu (ه)}

Department of Electronic Science \& Technology,

Huazhong University of Science and Technology, Wuhan 430074,

People's Republic of China

e-mail: jpxu@mail.hust.edu.cn

Fax: +86-27-87544406

C.X. Li · C.L. Chan · P.T. Lai ( $\varangle)$

Department of Electrical \& Electronic Engineering,

The University of Hong Kong, Pokfulam Road, Hong Kong,

Hong Kong

e-mail: laip@eee.hku.hk

Fax: +852-25598738

H.X. Xu

Department of Physics \& Electronic Technology,

Huanggang Normal University, Huangzhong 438000, People's

Republic of China

\section{Introduction}

As the Si-based metal-oxide-semiconductor field-effect transistor (MOSFET) is approaching its physical limit, germanium MOSFETs with high-permittivity (high- $k$ ) gate dielectric (e.g. $\mathrm{ZrO}_{2}$ [1], $\mathrm{HfO}_{2}$ [2-4], and $\mathrm{Al}_{2} \mathrm{O}_{3}$ [5]) are extensively discussed as alternative candidates for future complementary MOS technology due to the high carrier mobilities of germanium [6-8]. However, the growth of unstable and water-soluble germanium oxide during deposition and post-deposition annealing hinders the fabrication of competitive Ge-based MOS devices [9, 10]. To overcome this problem, various techniques including $\mathrm{NH}_{3}$ surface treatment [2-5] and Si interlayer [11, 12] have been applied in Ge-based MOS devices to enhance device performances. Recently, it was reported that rare-earth metal oxides such as $\mathrm{CeO}_{2}$ [13, 14], $\mathrm{Gd}_{2} \mathrm{O}_{3}$ [15] and $\mathrm{Dy}_{2} \mathrm{O}_{3}$ [16] produced promising electrical properties when directly in contact with Ge. Especially, $\mathrm{La}_{2} \mathrm{O}_{3}$ thin film shows many advantages, including low interface-states density, very small frequency dispersion and hysteresis due to formation of stable lanthanum germanate (La-Ge-O) [16-18]. However, a relatively low permittivity due to Ge diffusion into the high$k$ dielectric prevents further decrease in equivalent oxide thickness [17].

Ti incorporation has been studied by several groups to increase the permittivity of Hf-based oxides because of the extremely high relative permittivity $(k)$ of Ti-based oxides $(\sim 80)[19,20]$. Higher permittivity has been obtained with $\mathrm{Ti}$ incorporation while leading to a gate-leakage increase [21]. On the other hand, $\mathrm{N}$ incorporation in $\mathrm{HfO}_{2}$ results in beneficial characteristics including reduction of gate-leakage current, improved thermal stability of the dielectric material, due to suppression of the onset of dielectric crystallization $[22,23]$. In view of the above two effects 
on Hf-based oxides, it is expected that better dielectric properties could be achieved by simultaneously incorporating $\mathrm{Ti}$ and $\mathrm{N}$ into $\mathrm{La}_{2} \mathrm{O}_{3}$ thin film. Therefore, in this work, capacitors with LaTiON gate dielectric are fabricated and the impact of Ti content on the electrical properties of the capacitors is carefully examined. It is found that some electrical properties, e.g. $k$ value, interface-state density, gate-leakage current and device reliability, strongly depend on the Ti content incorporated in the $\mathrm{La}_{2} \mathrm{O}_{3}$ gate dielectric. When Ti content is set at an optimal value, a good trade-off among the electrical properties can be obtained.

\section{Experiments}

The used Ge substrate was (100) Sb-doped $n$-type Ge wafers with a resistivity of $0.10 \sim 0.11 \Omega \mathrm{cm}$. The wafers were cleaned in organic solvents, and lastly with de-ionized water rinsing followed by 30-s diluted HF (1:50) dipping for several cycles to remove the native oxide. After drying in $\mathrm{N}_{2}$, $\mathrm{LaON}$ thin film was deposited by sputtering of $\mathrm{La}_{2} \mathrm{O}_{3}$ target at a power of $30 \mathrm{~W}$ in $\mathrm{Ar}$ and $\mathrm{N}_{2}\left(\mathrm{Ar}: \mathrm{N}_{2}=24: 6\right)$ ambient at room temperature (denoted as LON). In order to investigate the impact of Ti content on the electrical properties of the capacitors, Ti was added into the $\mathrm{LaON}$ thin film by reactive co-sputtering of $\mathrm{Ti}$ and $\mathrm{La}_{2} \mathrm{O}_{3}$ targets with different Ti-target powers $(11.7 \mathrm{~W}, 17.4 \mathrm{~W}, 26.1 \mathrm{~W}$ and $33.3 \mathrm{~W})$ as shown in Table 1 (denoted as LTON1, LTON2, LTON3 and LTON4, respectively). All LaTiON films have roughly the same thickness $(7.5 \sim 7.8 \mathrm{~nm})$. A post-deposition annealing (PDA) was carried out in $\mathrm{N}_{2}$ ambient with a flow rate of $500 \mathrm{ml} / \mathrm{min}$ at $500^{\circ} \mathrm{C}$ for $5 \mathrm{~min}$. Subsequently, Al was evaporated and patterned by lithography as gate electrodes with an area of $A=7.85 \times 10^{-5} \mathrm{~cm}^{-2}$, followed by a forminggas annealing at $300^{\circ} \mathrm{C}$ for $20 \mathrm{~min}$.

High-frequency ( $\mathrm{HF}, 1-\mathrm{MHz}$ ) capacitance-voltage $(C-V)$ curves were measured by HP4284A precision LCR meter. Gate-leakage current was measured by HP4156A precision semiconductor parameter analyzer. Physical thickness of the

Table 1 Preparation conditions and physical thickness of the gate dielectrics. The $\mathrm{Ti} / \mathrm{La}_{2} \mathrm{O}_{3}$ ratio is calculated from the ratio of the deposition rates of $\mathrm{Ti}$ (at different sputtering powers) and $\mathrm{La}_{2} \mathrm{O}_{3}$ (at a sputtering power of $30 \mathrm{~W}$ ) in the same $\mathrm{Ar}: \mathrm{N}_{2}=24: 6$ ambient

\begin{tabular}{llll}
\hline Sample & $\begin{array}{l}\text { Ti-target power } \\
(\mathrm{W})\end{array}$ & $\begin{array}{l}\text { Physical } \\
\text { thickness }(\mathrm{nm})\end{array}$ & $\begin{array}{l}\mathrm{Ti} / \mathrm{La}_{2} \mathrm{O}_{3} \\
(\%)\end{array}$ \\
\hline LON & - & 8.05 & - \\
LTON1 & 11.7 & 7.47 & 7.3 \\
LTON2 & 17.4 & 7.55 & 14.7 \\
LTON3 & 26.1 & 7.60 & 23.8 \\
LTON4 & 33.3 & 7.83 & 34.0 \\
\hline
\end{tabular}

gate dielectrics was determined by a multi-wavelength ellipsometer and TEM. High-field stress $\left(10 \mathrm{MV} \mathrm{cm}^{-1}\right.$ for $3600 \mathrm{~s}$ ), with the capacitors biased in accumulation by the HP 4156A, was used to examine the device reliability in terms of gate-leakage increase and flatband-voltage shift. All electrical measurements were carried out under a lighttight and electrically-shielded condition at room temperature.

\section{Results and discussion}

The Ti content of the dielectric films is evaluated by the $\mathrm{Ti} / \mathrm{La}_{2} \mathrm{O}_{3}$ ratio, which is calculated from the ratio of the deposition rates of $\mathrm{Ti}$ (at different sputtering powers) and $\mathrm{La}_{2} \mathrm{O}_{3}$ (at a sputtering power of $30 \mathrm{~W}$ ) in the same Ar: $\mathrm{N}_{2}=$ 24:6 ambient, to represent the relative amount of $\mathrm{Ti}$ in the dielectric films.

Figures 1(a) and (b) show the TEM pictures of the LON and LTON2 samples, respectively. It can be seen that the interlayer between the high- $k$ dielectric and Ge substrate can be hardly observed in the two samples. This is ascribed to the $\mathrm{N}$ incorporation, which inhibits $\mathrm{O}$ diffusion and thus suppresses the formation of interlayer [24]. Comparing the two TEM pictures, it can be found that the interface is rougher for the LTON2 sample than the LON sample. A possible reason is that the incorporated $\mathrm{Ti}$ in LaTiON thin film strongly reacts with $\mathrm{Ge}$ at the surface of the Ge substrate [21].

Typical HF $C-V$ curves of the samples are depicted in Fig. 2. The four Ti-incorporated samples have larger accumulation capacitances $\left(C_{\mathrm{ox}}\right)$ than the LON sample, with larger $C_{\mathrm{ox}}$ for higher Ti-target power (thus higher Ti content), implying larger $k$ value and thus smaller capacitance equivalent thicknesses (CET) can be obtained for higher Ti content (LTON4 sample has the largest $k$ value of 30.8 and smallest CET of $1.0 \mathrm{~nm}$ ), as shown in Table 2. This should be attributed to an increase of Ti-based oxide in the LaTi-based oxide for higher Ti content, because Ti-based oxide has larger $k$ value than La-based oxide. However, the
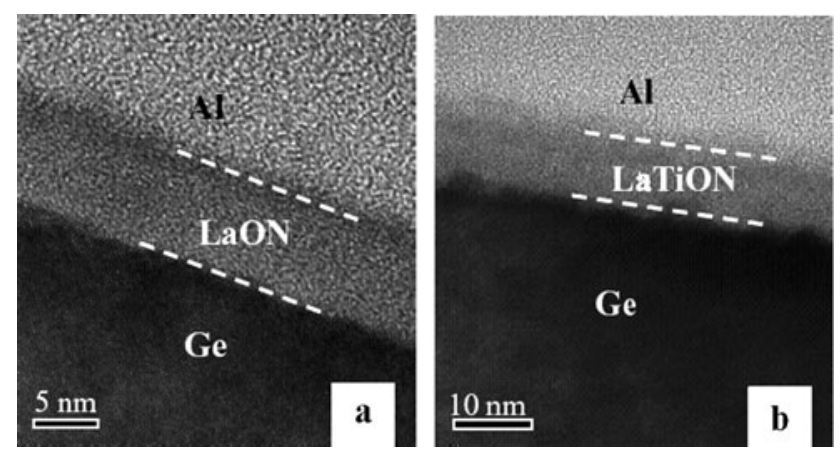

Fig. 1 TEM images of (a) LaON/Ge (LON), (b) LaTiON/Ge (LTON2) capacitors 
Table 2 Electrical parameters of the $n$-Ge MOS capacitors without or with Ti incorporation, extracted from 1-MHz $C-V$ curves

\begin{tabular}{llllll}
\hline Sample & $\begin{array}{l}C_{\mathrm{ox}} \\
(\mathrm{pF})\end{array}$ & $\begin{array}{l}C E T \\
(\mathrm{~nm})\end{array}$ & $\begin{array}{l}V_{f b} \\
(\mathrm{~V})\end{array}$ & $\begin{array}{l}Q_{\text {ox }} \\
\left(\mathrm{cm}^{-2}\right)\end{array}$ & $\begin{array}{l}D_{\text {it }} \\
\left(\mathrm{eV}^{-1} \mathrm{~cm}^{-2}\right)\end{array}$ \\
\hline LON & 129 & 2.1 & 0.19 & $-8.5 \times 10^{11}$ & $1.2 \times 10^{11}$ \\
LTON1 & 173 & 1.6 & 0.30 & $-2.7 \times 10^{12}$ & $2.4 \times 10^{11}$ \\
LTON2 & 227 & 1.2 & 0.34 & $-4.3 \times 10^{12}$ & $3.1 \times 10^{11}$ \\
LTON3 & 252 & 1.1 & 0.40 & $-6.0 \times 10^{12}$ & $1.2 \times 10^{12}$ \\
LTON4 & 274 & 1.0 & 0.46 & $-7.2 \times 10^{12}$ & 24.6 \\
\hline
\end{tabular}

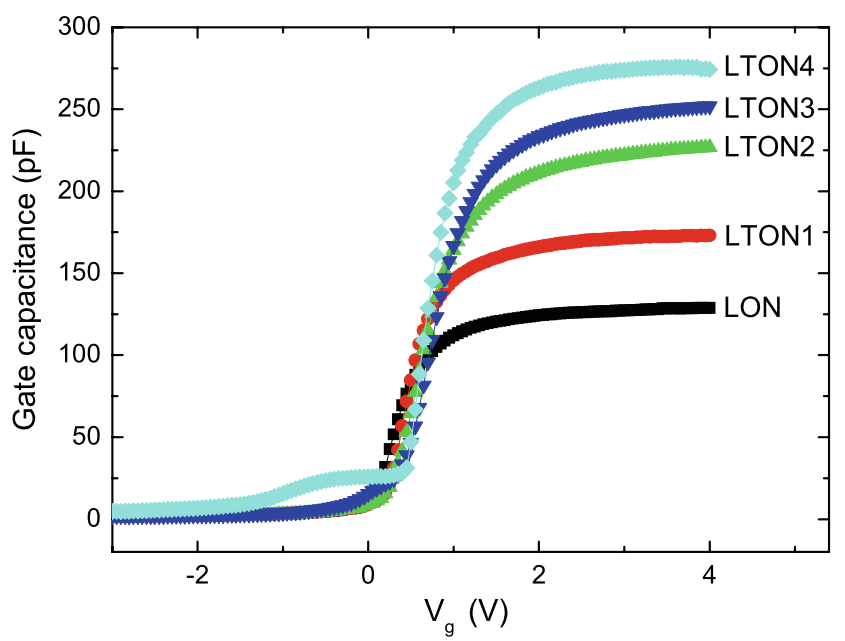

Fig. 2 High-frequency (1-MHz) $C-V$ curves for the $n$-Ge MOS capacitors without or with $\mathrm{Ti}$ incorporation

interface-state density $\left(D_{\text {it }}\right)$ increases with Ti content, which is obvious from the distorted $C-V$ curves of the LTON3 and LTON4 samples. This is confirmed by the extracted $D_{\text {it }}$ near midgap using Terman's method [25] for the purpose of comparison, with the largest $D_{\text {it }}$ for the LTON4 sample $\left(4.1 \times 10^{12} \mathrm{eV}^{-1} \mathrm{~cm}^{-2}\right)$, as shown in Table 2. This is probably associated with the fact that stronger reaction between the Ge substrate and LaTiON film could happen as the Ti content increases, similar to the situation of HfTiO in contact with Ge [21]. The higher equivalent oxide-charge density $\left(Q_{\mathrm{ox}}\right)$ of the Ti-incorporated samples should be mainly due to the high oxide charges near the interface and interface trap charges. The negative $\mathrm{Q}_{\mathrm{ox}}$ indicates that these traps could be acceptor-like interface and near-interface traps due to the Ge diffusion from the substrate into the high- $k$ layer and the reaction between $\mathrm{Ge}$ and Ti near the interface. So, a trade-off consideration between $k$ and $D_{\text {it }}$ is necessary when Ti is added into $\mathrm{LaON}$, e.g. for our studied range of Ti-target power, a sputtering power of $17.4 \mathrm{~W}$ (LTON2 sample) seems to be suitable, producing a relatively high- $k$ value (24.6) and relatively low $D_{\text {it }}\left(3.1 \times 10^{11} \mathrm{eV}^{-1} \mathrm{~cm}^{-2}\right)$. Further optimization of the Ti content is necessary for obtaining better trade-off among the device properties.

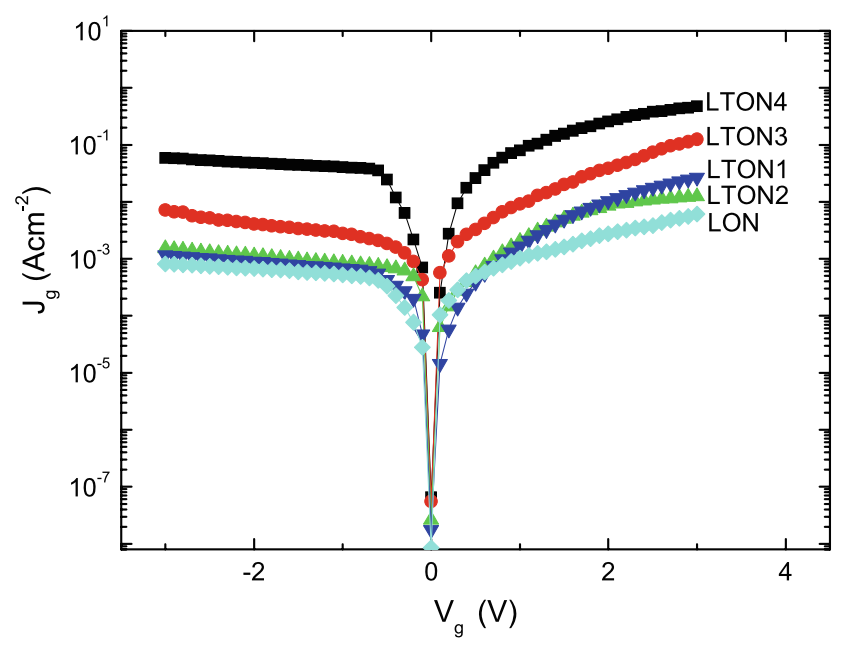

Fig. 3 Gate-leakage current density $\left(J_{g}\right)$ vs. gate voltage $\left(V_{g}\right)$ for the $n$-Ge MOS capacitors without or with Ti incorporation

The gate-leakage properties of the samples are illustrated in Fig. 3. Obviously, the Ti-incorporated samples exhibit larger gate-leakage current than the LON sample, and the higher the Ti content, the larger is the gate-leakage current. The gate-leakage current density $\left(J_{g}\right)$ of the LTON4 sample is $8.1 \times 10^{-2} \mathrm{~A} \mathrm{~cm}^{-2}$ at $V_{g}=1 \mathrm{~V}$, which is nearly 80 times higher than that of the LON sample $\left(1.0 \times 10^{-3} \mathrm{~A} \mathrm{~cm}^{-2}\right)$ and 40 times higher than that of the LTON1 sample $(1.7 \times$ $10^{-3} \mathrm{~A} \mathrm{~cm}^{-2}$ ), although they have almost the same gatedielectric thickness. This should be closely related to the gradually deteriorated quality of the dielectric/Ge interface as the Ti content increases (see Table 2 and Fig. 2). For the LTON2 sample with relatively few interface defects, an acceptably small $J_{g}$ of $2.0 \times 10^{-3} \mathrm{~A} \mathrm{~cm}^{-2}$ can be obtained at $V_{g}=1 \mathrm{~V}$.

In order to investigate the device reliability, a high-field stress at $10 \mathrm{MV} \mathrm{cm}^{-1}$ for $3600 \mathrm{~s}$ is performed on the capacitors, with the samples biased in accumulation. Their HF (1-MHz) $C-V$ curves and gate-leakage currents before and after the stress are measured. The shift of flatband voltage ( $\triangle V_{f b}$ ) extracted from the $C-V$ curve and the increase of gate-leakage current density $\left(\triangle J_{g}\right)$ at $V_{g}=1 \mathrm{~V}$ are summarized in Fig. 4. Obviously, the four Ti-incorporated samples 


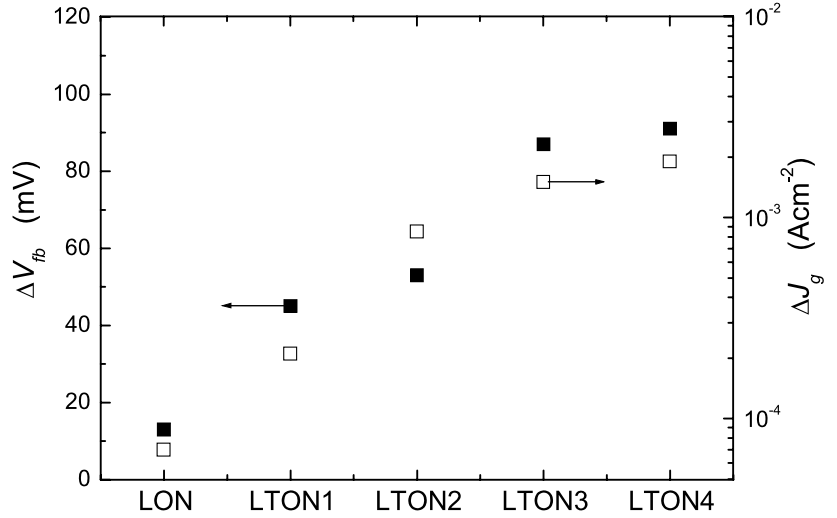

Fig. 4 Flatband-voltage shift $\left(\triangle V_{f b}\right)$ and gate-leakage increase $\left(\triangle J_{g}\right)$ at $V_{g}=1 \mathrm{~V}$ for the $n$-Ge MOS capacitors without or with Ti incorporation after a high-field stress (at $10 \mathrm{MV} / \mathrm{cm}$ for $3600 \mathrm{~s}$ )

have larger $\triangle V_{f b}$ and $\triangle J_{g}$ than the LON sample, which should be attributed to the poor interface quality associated with Ti-induced defects [26]. So, the Ti-target power and thus Ti-content control is the key for excellent electrical properties of the LaTi-based gate-dielectric MOS devices.

\section{Conclusions}

The effects of $\mathrm{Ti}$ incorporation into $\mathrm{LaON}$ gate dielectric on the electrical properties of MOS capacitors have been investigated. Results indicate that $\mathrm{Ti}$ addition can significantly increase the $k$ value and decrease $C E T$ due to the extremely high permittivity of Ti-based oxides, but deteriorate the dielectric/Ge interface quality, and thus gate leakage properties and device reliability due to Ti-induced defects. Therefore, the $\mathrm{Ti}$ content incorporated into $\mathrm{LaON}$ has to be carefully chosen to achieve a good trade-off between the $k$ value and $D_{\text {it }}$. For our Ti-incorporated samples, a suitable $\mathrm{Ti} / \mathrm{La}_{2} \mathrm{O}_{3}$ ratio of $14.7 \%$ leads to a high $k$ value of 24.6 , low interface-state density of $3.1 \times 10^{11} \mathrm{eV}^{-1} \mathrm{~cm}^{-2}$, relatively low gate-leakage current density of $2.0 \times 10^{-3} \mathrm{~A} \mathrm{~cm}^{-2}$ at $V_{g}=1 \mathrm{~V}$ and good device reliability.

Acknowledgements This work is financially supported by the National Natural Science Foundation of China (Grant No. 60776016), the RGC of HKSAR, China (Project No. HKU 713308E), and the University Development Fund (Nanotechnology Research Institute, 00600009) of the University of Hong Kong.

Open Access This article is distributed under the terms of the Creative Commons Attribution Noncommercial License which permits any noncommercial use, distribution, and reproduction in any medium, provided the original author(s) and source are credited.

\section{References}

1. C.O. Chui, H. Kim, D. Chi, B.B. Triplett, P.C. McIntyre, K.C. Saraswat, in IEEE IEDM Tech. Dig. (2002), p. 437
2. W.P. Bai, N. Lu, J. Liu, A. Ramirez, D.L. Kwong, D. Wristers, A. Ritenour, L. Lee, D. Antoniadis, in VLSI Symp. Tech. Dig. (2003), p. 121

3. A. Ritenour, S. Yu, M.L. Lee, N. Lu, W. Bai, A. Pitera, E.A. Fitzgerald, D.L. Kwong, D.A. Antoniadis, in IEEE IEDM Tech. Dig., Washington, DC, USA, December 8-10, 2003, p. 433

4. C.O. Chui, H. Kim, P.C. Mcintyre, K.C. Saraswat, in IEEE IEDM Tech. Dig., Washington, DC, USA, December 8-10, 2003, p. 437

5. J.J. Chen, N.A. Bojarczuk, H. Shang, M. Copel, J.B. Hannon et al., IEEE Trans. Electron. Dev. 51, 1441 (2004)

6. A. Ritenour, S. Yu, M.L. Lee, N. Lu, Wu. Bai, A. Pitera, E.A. Fitzgerald, D.L. Kwong, and D.A. Antoniadis, in IEEE IEDM Tech. Dig., vol. 433, Washington, DC, USA, December 8-10, 2003, p. 18.2 .1

7. P. Zimmerman, G. Nicholas, B. De Jaeger, B. Kaczer, A. Stesmans, L.A. Ragnarsson, D.P. Brunco, F.E. Leys, M. Caymax, G. Winderickx, K. Opsomer, M. Meuris, M.M. Heyns, in IEEE IEDM Tech. Dig., San Francisco, USA, December 10-13, 2006, p. 655

8. S. Joshi, C. Krug, D. Heh, H.J. Na, H.R. Harris, J.W. Oh, P.D. Kirsch, P. Majhi, B.H. Lee, H.-H. Tseng, R. Jammy, J.C. Lee, S.K. Banerjee, IEEE Electron. Dev. Lett. 28, 308 (2007)

9. N. Wu, Q. Zhang, C. Zhu, C.C. Yeo, S.J. Whang, D.S.H. Chan, M.F. Li, B.J. Cho, A. Chin, D.-L. Kwong, A.Y. Du, C.H. Tung, N. Balasubramanian, Appl. Phys. Lett. 84, 3741 (2004)

10. Y.A. Hu, J.-T. Zettler, S. Chongsawangvirod, Y.Q. Wang, E.A. Irene, Appl. Phys. Lett. 61, 1098 (1992)

11. W.P. Bai, N. Lu, D.-L. Kwong, IEEE Electron. Dev. Lett. 26, 378 (2005)

12. N. Wu, Q. Zhang, C. Zhu, D.S.H. Chan, A. Du, N. Balasubramanian, M.F. Li, A. Chin, J.K.O. Sin, D.-L. Kwong, IEEE Electron. Dev. Lett. 25, 631 (2004)

13. D.P. Brunco, A. Dimoulas, N. Boukos, M. Houssa, T. Conard, K. Martens, C. Zhao, F. Bellenger, M. Caymax, M. Meuris, M.M. Heyns, J. Appl. Phys. 102, 24104 (2007)

14. G. Nicholas, D.P. Brunco, A. Dimoulas, J. van Steenbergen, F. Bellenger, M. Houssa, M. Caymax, M. Meuris, Y. Panayiotatos, A. Sotiropoulos, IEEE Trans. Electron. Dev. 54, 1425 (2007)

15. C.H. Lee, T.D. Lin, L.T. Tung, M.L. Huang, M. Hong, J. Kwo, J. Vac. Sci. Technol. 26, 1128 (2008)

16. A. Dimoulas, D.P. Brunco, S. Ferrari, J.W. Seo, Y. Panayiotatos, Thin Solid Films 515, 6337 (2007)

17. G. Mavrou, S. Galata, P. Tsipas, A. Sotiropoulos, Y. Panayiotatos, A. Dimoulas, E.K. Evangelou, J.W. Seo, Ch. Dieker, J. Appl. Phys. 103, 14506 (2008)

18. J. Song, K. Kakushima, P. Ahmet, K. Tsutsui, N. Sugii, T. Hattori, H. Iwai, Microelectron. Eng. 84, 2336 (2007)

19. N. Lu, H.J. Li, J.J. Peterson, D.L. Kwong, Appl. Phys. Lett. 90, 82911 (2007)

20. V.V. Afanasev, A. Stesmans, F. Chen, M. Li, S.A. Campbell, J. Appl. Phys. 95, 5583 (2004)

21. C.X. Li, X. Zou, P.T. Lai, J.P. Xu, C.L. Chan, Microelectron. Reliab. 48, 526 (2008)

22. M.R. Visokay, J.J. Chambers, A.L.P. Rotondaro, A. Shanware, L. Colombo, Appl. Phys. Lett. 80, 3183 (2002)

23. C.H. Choi, T.S. Jeon, R. Clark, D.L. Kwong, IEEE Electron Dev. Lett. 24, 215 (2003)

24. P.S. Lysaght, J. Barnett, G.I. Bersuker, J.C. Woicik, D.A. Fischer, B. Foran, H.H. Tseng, R. Jammy, J. Appl. Phys. 101, 24105 (2007)

25. L.M. Terman, Solid State Electron. 5, 285 (1962)

26. H. Arimura, N. Kitano, Y. Naitou, Y. Oku, T. Minami, Appl. Phys. Lett 92, 212902 (2008) 